\title{
CRITÉRIOS DE AUTORIA E CO-AUTORIA EM TRABALHOS CIENTÍFICOS ${ }^{1}$
}

\author{
Mario R. Montenegro ${ }_{3}^{2}$ \\ Venâncio A. Ferreira Alves
}

Cada vez que consultamos uma revista científica, especialmente aquelas voltadas à ciência médica, deparamos com trabalhos apresentados por numerosos autores. Aliás, este problema é internacional e já existem na literatura recente vários artigos abordando o assunto (Editorial 1985; Huth 1985; ICMJE 1985; D’Assumpção 1986). Nós, sendo patologistas e envolvidos em pesquisa, somos solicitados a participar de trabalhos das mais variadas especialidades e freqüentemente nos vemos na contingência de decidir quem deve ser incluído na lista de autores e qual a ordem em que seus nomes deverão ser nela dispostos. Por outro lado, participando do Conselho Editorial de algumas revistas, temos nos surpreendido com a dificuldade em identificar o papel desempenhado pelos diferentes co-autores de um artigo que devemos analisar.

De nossas discussões emergiu uma série de critérios que, na sua maioria, estão de acordo com proposições semelhantes encontradas na literatura (Editorial 1985; Huth 1985; ICMJE 1985; D'Assumpção 1986) e que consideramos oportuno divulgar.

A maioria dos trabalhos publicados em nossa área pode ser descrita como objetivando resumir e criticar os conhecimentos a respeito de um tema, descrever um fato, um fenômeno ou uma técnica, descrever um conjunto de fatos ou fenômenos e, eventualmente, classificá-los, descrever a evolução temporal de um evento, comparar diferentes aspectos de um fenômeno pouco conhecido ou pouco freqüente ou, ainda, testar hipóteses que tenham sido geradas a partir da observação dos fatos e de sua correlação com o conhecimento anterior.

Cada um destes modelos pressupõe o esforço de mais de uma pessoa e nossa intenção é a de discutir normas que possam definir quais delas deverão ser incluídas na lista de co-autores por ocasião de uma publicação.

Um trabalho, qualquer que seja a sua natureza, terá um indivíduo que o idealizou, que definiu seus objetivos, que decidiu qual o material a ser estudado e qual o método

\footnotetext{
Trabalho reproduzido da Revista do Instituto de Medicina Tropical de São Paulo 29(4): 191-193. 1987, com autorização e por especial cortesia dos autores.

Faculdade de Medicina de Botucatu, UNESP, CEP 18603-970, Botucatu, São Paulo, Brasil

Faculdade de Medicina da Universidade de São Paulo e Instituto Adolfo Lutz da Secretaria da Saúde do Estado de São Paulo, Av. Dr. Arnaldo, 355, CEP 01255-090, São Paulo, SP, Brasil
} 
a ser empregado e que também, em geral, é o responsável pela análise final dos resultados obtidos. Esta pessoa nem sempre domina tecnicamente muitos ou todos os métodos utilizados no trabalho; deverá, porém, ser a autora principal e seu nome deverá figurar como o primeiro da lista de autores.

Quanto aos demais colaboradores, um deles pode ser facilmente caracterizado. Trata-se de alguém bastante experiente que é consultado nas diferentes fases de elaboração do trabalho e especialmente no seu delineamento, nas discussões sobre a interpretação dos resultados e na revisão final do manuscrito. Esta pessoa que poderia ser denominada de "orientador" ou de "guru" do grupo poderá ou não figurar entre os autores; quando o faz, lhe é tradicionalmente reservado o último lugar na lista de autores. Quando não entrar no trabalho, sua colaboração, imprescindível, deve ser registrada nos agradecimentos. A decisão sobre sua inclusão ou não deverá ser tomada em discussão franca entre os diferentes colaboradores e seu nome só poderá ser incluído com a sua anuência.

Um dos abusos cometidos com frequiência é o da inclusão, como último autor, do chefe do grupo, tenha ele participado ou não do trabalho. Isto é feito com dois objetivos, ambos reprováveis: agradar o chefe ou usar o seu nome e prestígio para valorizar o trabalho.

Por outro lado, há chefes que fazem questão de que seu nome seja incluído em todos os trabalhos de seu grupo. Não é necessário enfatizar o absurdo desta posição que por si define um baixo nível ético que certamente se reflete na seriedade com que o trabalho foi realizado e até põe em dúvida seus resultados.

Quanto aos outros co-autores, vários critérios poderão ser adotados, como por exemplo, a ordem de importância de sua contribuição, ou a ordem alfabética. Aliás, esta última solução tem sido adotada quando se trata de trabalhos que reflitam decisões de grupos de estudo ou comitês, relatórios de mesas redondas, simpósios, etc.

Outro abuso, freqüente, é o de incluir como co-autor, por "cortesia" amigos ou colegas. Esta política cria um sistema imoral de trocas de favores e permite que pessoas totalmente desligadas do assunto sejam, até sem o saber, incluídas como co-autores. Neste ponto, parece-nos útil lembrar que o fato de ter o nome listado entre os autores de determinado trabalho se, de um lado, pode enriquecer o currículo de um profissional, de outra parte, quando se caracterizam falhas no estudo, pode lançar dúvidas ou mesmo denegrir todo um passado de atividades.

Recentemente 47 eminentes co-autores de trabalhos realizados por um célebre falsário, J. Darsee, foram chamados a explicar sua participação nas falsificações e tiveram sua reputação atingida, pois foi demonstrado que, ao aceitar a co-autoria, não tinham analisado com profundidade os trabalhos, co-honestando assim a divulgação da fraude (Culliton 1987).

É necessário entender que a inclusão como co-autor de um artigo pressupõe envolvimento importante na sua realização, conhecimento de seu conteúdo e participação na sua redação. Por outras palavras, o co-autor é corresponsável pelo trabalho e responde por ele.

Aceita a premissa de que os co-autores são corresponsáveis pelo trabalho, fica mais fácil identificar quais os colaboradores que devem ser incluídos como co-autores. 
Para fazê-lo, é necessário que se defina qual o tipo de participação dos vários colaboradores, e mais uma vez, por consenso, decidir como incluir cada um deles.

Este assunto vem sendo cada vez mais debatido e já se constituiu em manifestação oficial do International Committee of Medical Journal Editors (ICMJE 1985). Esta publicação foi favoravelmente comentada pelo Lancet (Editorial 1985) e, em artigo de Huth (1985) que aborda o tema em um conjunto de artigos sobre fraude em ciências médicas, publicado no Annals of International Medicine. No Brasil, foi há poucos meses abordado por D'Assumpção (1986), em carta aos Editores da Revista da Associação Médica Brasileira.

As recomendações da ICMJE (1985) são bastante claras e, na nossa opinião, deveriam ser incorporadas à política editorial das revistas médicas nacionais.

É nesse sentido que a seguir traduziremos algumas das suas recomendações.

Cada autor deve ter participado suficientemente do trabalho para poder assumir publicamente a responsabilidade pelo seu conteúdo (o grifo é nosso). Sua participação deve incluir: a) a concepção ou delineamento ou ainda análise e interpretação dos dados, ou ambos; b) redação do manuscrito ou sua revisão, quando inclua crítica intelectual importante de seu conteúdo; c) aprovação final da versão a ser publicada. A simples participação na coleta de dados não justifica autoria (o grifo é nosso).

Todos os elementos de um artigo (a, b, e c acima) devem ser atribuíveis a pelo menos um autor.

Em um trabalho de grupo (coletivo) a autoria deve especificar as pessoas-chave responsáveis pelo artigo; os outros colaboradores devem ser reconhecidos separadamente.

Os Editores podem requerer dos autores que justifiquem sua inclusão na autoria do trabalho (o grifo é nosso).

Em um lugar apropriado do trabalho (página frontal, rodapé ou apêndice ao texto, de acordo com o periódico) uma ou mais declarações devem especificar: a) contribuições que merecem reconhecimento mas não justifiquem autoria b) reconhecimento de auxílio técnico; c) reconhecimento de auxílio financeiro ou material; d) explicação sobre auxílios financeiros que possam causar conflitos de interesse.

Pessoas que tenham contribuído intelectualmente para os artigos, cuja participação não justifique autoria, devem ser referidas e sua colaboração descrita como, por exemplo, "orientação", "revisão crítica", "coleta de dados", "participação em inquérito clínico". Estas pessoas precisam dar permissão antes de ser assim citadas.

O auxílio técnico deve ser agradecido em um parágrafo separado. Auxílios materiais ou financeiros de qualquer fonte devem ser também especificados.

Ao comentar estas Guidelines on Authorship do ICMJE (1985), o editorial do Lancet (Editorial 1985) diz que espera que estas recomendações sobre autoria "façam alguma coisa para limitar a tendência à inflação em número de autores, como também, pela sua ênfase na responsabilidade, seja um obstáculo aos Munchausens da Medicina". Continua dizendo que as recomendações "levam em conta não só os que estão incluídos e não deveriam estar, como também aqueles que estão ausentes, mas deveriam estar presentes". 
Huth (1985), por outro lado, aborda o tema sob o ponto de vista da ética, fala de autoria injustificada e diz que o abuso na autoria raramente interfere com a eficiência da ciência ou reduz suas fontes, porém, corrói a ética e a honestidade. Como remédios ele recomenda, como faz o ICMJE (1985) que os periódicos solicitem "a exata contribuição de cada um dos co-autores de forma a justificar a co-autoria". Cita ainda uma exigência do Annals of Internal Medicine, revista em que, para que o trabalho seja aceito, "cada autor deve afirmar que leu a versão final do trabalho e concorda com a sua publicação".

D’Assumpção (1986) chama a atenção para vários dos tópicos já comentados e acrescenta sua preocupação com as conseqüências que a co-autoria irresponsável possa vir a ter sobre a avaliação de pesquisadores. Comenta que, em algumas instituições, a co-autoria começa a não ser considerada nas avaliações, com evidente prejuízo para os co-participantes legítimos. Este ponto de vista é compartilhado por outros (Petersdorf 1985) que chegam a afirmar que trabalhos com múltiplos autores são, freqüentemente, revistos de forma incompleta, perdendo portanto em qualidade, o que acaba justificando a tendência de desvalorizá-los.

Ao divulgar nossa preocupação com este tema nosso objetivo principal é de que seja ele debatido em nosso meio e sirva de estímulo para que nossas revistas introduzam em seus critérios de aceitação de trabalhos, as normas que vêm sendo propostas em nível internacional. Acreditamos, firmemente, que estes cuidados facilitarão, inclusive o julgamento de memoriais nos concursos universitários, podendo valorizar mais as participações efetivas em trabalhos de qualidade, e menos a simples quantidade.

\section{Referências bibliográficas}

Culliton, B.J. 1987. Integrity of research papers questioned. Science 235: 422-423.

D’Assumpção, E.A. 1986. A ética da co-autoria. Revista da Associação Médica Brasileira 32: 283-284.

Editorial. 1985. Consensus on authorship and other matters. Lancet 2: 595.

Huth, E.J. 1985. Irresponsible authorship and wasteful publication. Annals of International Medicine 104: 257-259.

ICMJE. 1985. International Committee of Medical Journal Editors Guidelines on Authorship. British Medicine Journal 291: $722-724$.

Petersdorf, R.G. 1985. The pathogenesis of fraud in medical science. Annals of International Medicine 104: 252-254. 